ISSN 0103-5150

Fisioter. Mov., Curitiba, v. 30, n. 3, p. 569-577, Jul./Sep. 2017

Licenciado sob uma Licença Creative Commons

DOI: http://dx.doi.org/10.1590/1980-5918.030.003.A015

(c)

\title{
Multidimensional features of pain in patients with chronic neck pain
}

\section{Características multidimensionais da dor em indivíduos com cervicalgia crônica}

\author{
Fabianna Resende de Jesus-Moraleida ${ }^{[a, b]}$, Leani Souza Máximo Pereira ${ }^{[b]}$, \\ Cristiane de Melo Vasconcelos ${ }^{[b]}$, Paulo Henrique Ferreira ${ }^{[c] *}$ \\ [a] Universidade Federal do Ceará (UFC), Fortaleza, CE, Brazil \\ [b] Universidade Federal de Minas Gerais (UFMG), Belo Horizonte, MG, Brazil \\ [c] University of Sydney (USYD), Sydney, Australia
}

\begin{abstract}
Introduction: Chronic neck pain is associated with significant health costs and loss of productivity at work. Objective: to assess pain and disability in individuals with chronic neck pain. Methods: 31 volunteers with chronic neck pain, mean age 29, 65 years, were assessed using the McGill Pain Questionnaire in Brazilian version (Br-MPQ) and Neck Disability Index (NDI). The Br-MPQ analysis was performed based on the numerical values associated with the words selected to describe the experience of pain (Pain Rating Index - PRI), and present pain intensity (PPI). NDI was used to evaluate the influence of neck pain in performance of everyday tasks. Finally, we investigated the association between PPI and NDI. Results: PRI revealed that the most significant dimension was the sensory pain (70\%), and the number of chosen words was $10(2,62)$ out of 20 words. Mean PPI value was $1,23(0,76)$ in five points; $40 \%$ of participants described pain intensity as moderate. NDI score was 9,77 $(3,34)$, indicating mild disability. There was a positive association between disability and pain intensity $(r=0,36 ; p=0,046)$. Pain intensity and duration of pain were not associated. Conclusions: Findings of this study identified important information related to neck pain experienced by patients when suffering
\end{abstract}

* FRJM: PhD, e-mail: fabiannamoraleida@gmail.com LSMP: PhD, e-mail: leanismp.bh@terra.com.br CMV: MS, e-mail: cristianedemelo@gmail.com PHF: PhD, e-mail: paulo.ferreira@sydney.edu.au 
from chronic neck pain, moreover, the association between disability and pain intensity reinforces the importance of complementary investigation of these aspects to optimize function in them.

Keywords: Neck Pain. Questionnaires. Chronic Pain. Pain Measurement.

\section{Resumo}

Introdução: A cervicalgia crônica está associada a importantes gastos em saúde e à perda de produtividade no trabalho. Objetivo: Avaliar aspectos de dor e incapacidade de indivíduos com cervicalgia crônica. Métodos: Trinta e um voluntários com cervicalgia crônica, com média de idade de 29, 65 anos, foram avaliados por meio do questionário de dor de McGill em versão brasileira-Br-MPQ (Br-MPQ) e pelo Índice de Incapacidade Relacionada ao Pescoço (NDI). A análise do Br-MPQ foi realizada baseando-se nos valores numéricos associados com as palavras de descrição da experiência da dor (Pain Rating Index - PRI), e na intensidade da dor presente (Present Pain Index - PPI). O NDI foi utilizado para avaliar a interferência da cervicalgia pelos participantes no desempenho de tarefas cotidianas. Finalmente, foi investigada a associação entre o PPI e o NDI. Resultados: A dimensão mais significativa de dor no PRI foi sensorial (70\%), e número de descritores escolhidos para descrevê-la foi $10(2,62)$ em 20.0 valor médio do PPI de $1,23(0,76)$ em cinco pontos; $40 \%$ dos participantes descreveram a intensidade de dor como moderada. A pontuação do NDI foi de $9,77(3,34)$, indicando incapacidade leve. Houve associação positiva entre intensidade de dor e incapacidade ( $r=0,36 ; p=0,046)$; mas não entre intensidade e duração da dor. Conclusão: Os resultados identificaram características importantes diante da experiência de pacientes com cervicalgia crônica e, além disso, a associação entre incapacidade e dor observada reforça a importância da abordagem destes itens de maneira complementar destes fatores para favorecer a funcionalidade destes pacientes.

Palavras-chave: Cervicalgia. Questionários. Dor Crônica. Medição da Dor.

\section{Introduction}

Neck related dysfunctions have become considerably prevalent in society, especially chronic neck pain, which is considered a common source of disability in the economically active population (1-4). Estimates from the Global Burden of Disease 2010 study point that, overall, the average prevalence of neck pain is $4.9 \%$ (95\% confidence interval - 95\% CI: 4.6 to 5.3 ) and that neck pain was the fourth major condition among the 291 investigated health conditions to generate disability (1). Neck pain is associated with high health costs and significant levels of absenteeism at work (5-7). Hogg-Jonhson (4) points to a 12-months neck pain prevalence varying from 30 to $50 \%$ in the general population, and that its associated disability ranges from 1.7 and $11.5 \%$. The increase of levels of sedentarism in the population, the use of computers in the work environment and its associated work postures are factors that can predispose an increase in the ocurrence of neck pain $(4,8)$. The literature indicates significant associations between neck pain and working environment related factors, such as being female (risk ratio $=2.4,95 \% \mathrm{CI}=0.9-6.5$ ) (9), sitting for prolonged periods of time (Odds ratio - OR $=2.0,95 \% \mathrm{CI}=1.2$ to 3.4 ), maintaining excessively the head in a protrusion posture $(\mathrm{OR}=2.0,95 \% \mathrm{CI}=1.2$ to 3.6) (10), and to the continuous repetition of upper limb movements (OC $=1.6,95 \% \mathrm{CI}=1.0$ to 2.6$)(10)$.

Psychosocial issues related to increased occupational demand and consequent stress have also been reported as important risk factors for the development of complaints of shoulder and neck pain (10-12). Data on disability pensions by the Brazilian Social Security Institute indicate that spinal pain is a commonly observed condition in the general population, which has a significant economic impact in Brazil, being the main cause of early retirement due to sickness in 2007 (13). The course of neck pain in workers is persistent or recurrent in most cases, and more than $60 \%$ of them will present recurrence in one year (2). Thus, knowledge of neck pain related factors is of great importance, not only for the relief of symptoms, but especially for the prevention of 
recurrent episodes of pain, personal suffering and loss of productivity at work $(5,8)$.

Due to the multidimensional repercussions associated with chronic neck pain, it is important to consider the individual's perspective regarding this condition. One of the most appropriate ways in clinical practice to evaluate patient's perception of the impact of a particular health condition perceived on its functioning is the use of questionnaires. The McGill Pain Questionnaire (MPQ), an instrument already adapted and validated for the Brazilian population (Br-MPQ) (14-16), can be used both in scientific and clinical settings for comprehensive pain evaluation. Its analysis can be performed qualitatively and quantitatively in relation to the evaluation of the pain descriptors. The Neck Disability Index (NDI), also reliable and adapted for the Brazilian population (17), provides the examiner information about how neck pain affects the individual's ability to perform daily activities.

Despite the relevance of understanding neck pain impact from patients' perspective, there are limited studies describing aspects related to the experience of chronic neck and its associated disabilities in Brazilians. Furthermore, we found little discussion about the qualitative and quantitative aspects of chronic neck pain, by means of an objective and consistent measurement. Therefore, the objectives of this study were to identify the multidimensional characteristics of pain, and to evaluate the association between the pain experience and the perceived disability of individuals with chronic neck pain.

\section{Methods}

Study design: cross-sectional study conducted with adults with chronic neck pain.

\section{Participants}

Thirty-one volunteers with chronic neck pain, aged between 18 and 55 years, participated in the study. This sample was selected for convenience among local University students and employees and from the general community, including those in waiting lists for physical rehabilitation services in Belo Horizonte/Brazil due to their neck complaint, regardless of gender or socioeconomic level. All participants signed a free and informed consent term, agreeing to participate in this study, which was approved by the Research Ethics Committee of Universidade Federal de Minas Gerais - UFMG (ETIC 358/08). The study was carried out at the Laboratory of Pain and Inflammation in Rehabilitation and Aging Studies (LADIRE), UFMG.

The inclusion criteria for the study sample were: aged between 18 and 55 years; being able to understand and perform the procedures proposed by the study; history of non-specific cervicalgia with a minimum duration of at least three months that interefere in their performance of daily and/or occupational activities. Chronic neck pain was defined for the present study according to the latter criterion. The exclusion criteria were: root pain signs and symptoms identified in the initial evaluation phase by a physiotherapist; clinical diagnosis of either autoimmune, rheumatic diseases, tumors or infections in the cervical spine, neurological diseases with motor sequelae, neoplasias; Evident cervical or thoracic deformity; having had cervical spine surgery in the previous 12 months; diagnosis of fracture or history of trauma in the cervical spine or temporomandibular joint; having made continuous use of muscle relaxant, analgesic or anti-inflammatory within 48 hours prior to data collection; having performed or been under physiotherapy treatment for the cervical spine within the previous three months to data collection. Due to the interference of depression in the manifestation of pain, participants were also excluded when presenting depressive symptoms according to Beck Depression Inventory cut-off point (score $\geq 20$ / 63) (18).

\section{Instruments and Outcomes}

Prior to participants' evaluation, the research team informed volunteers about the purposes, related clinical relevance and data collection procedures related to the research. Only after signing the consent form, participants responded to a socio-clinical-demographic questionnaire developed by the research team for characterization, including time of pain onset. Then, a single and previously trained examiner assessed participants for investigating multidimensional aspects related to neck pain through Br-MPQ $(14,15)$, and neck pain related disability by NDI $(17)$. 
Brazilian version of the McGill Pain Questionnaire: $B r-M P Q$

This questionnaire was adapted for the Brazilian population (intra- and inter-examiner reliability of $r$ $=0.86$ and 0.89 , respectively) (15). It consists of four parts: location of pain, beginning and treatments performed, temporal pattern and description of pain and intensity of present pain (16). The first part presents a schematic drawing of the human body, in which the individual locates the area of his pain at the moment of the evaluation. In the second part, participants report data related to the type of treatment performed for pain relief and their perceived patterns of pain over time. The third part of the questionnaire includes the more specific characteristics of the questionnaire. Initially, the individual describes his pain spontaneously, through freely chosen words. Then, sets of words described and with pre-established values in ascending order of intensity (total of 68) are read by the evaluator so that, in each group of these, the individual can choose if any describes his pain. The categories for each word are sensorial (maximum of 34 points), affective (17 points), evaluative (5) and mixed (12), and they are subdivided into 20 subcategories in total. The individual can select only one word per subcategory, and can choose not to choose any word in the subcategory. In addition to punctuating each of these subcategories, one can evaluate the number of words chosen, in a total of 20 points (16).

Finally, the fourth part of the questionnaire evaluates the intensity of present pain (Present Pain Index - PPI), according to the descriptors: painless (0), weak (1), moderate (2), strong (3), violent (4) and unbearable (5). The analysis of the questionnaire can be performed qualitatively and quantitatively in relation to the evaluation of the pain descriptors, based on the numerical values associated with the words of description within each subcategory of the third part of the questionnaire (PRI), as well as the number of words chosen in this part of the same (Number of Chosen Words - NCW) (16).

\section{Neck Disability Index (NDI)}

NDI (17) is both reliable (intraclass correlation index - ICC $=0.93,95 \% \mathrm{CI}=0.86$ to 0.97 ) (20) and validated for the Brazilian population (test-retest reliability of 0.98 on the first day and 0.48 on the seventh day) (17). It consists of 10 sections punctuated from
0 to 5 each, and can determine the level of disability due to neck pain. The higher the score obtained, the greater neck pain interference in daily routine. Its scores can be categorized into five categories, which are: scores from 0-4 indicates no disability; 5-14 indicates mild disability, 15-24 moderate disability, and 25-34 severe disability. Finally, individuals who score the questionnaire from 35 points are considered completely disabled due to neck pain. Noteworthy, NDI and SF-36 questionnaires are correlated $(r=-0.82 ; p$ $<0$.011) (19); also, NDI is compatible with descriptors associated with the International Classification of Functioning and Health - CIF (20).

\section{Statistics}

Sample characterization and Br-McGill and NDI questionnaire components were expressed as mean and standard deviation values. Then, we calculated weighted avarages for all PRI dimensions, that was measured by the ratio of the mean score in the category to the possible score number in that category. The closer to the value of 1 , the more the category was represented within the overall dimension of pain. Spearman's correlation test was used to investigate possible correlations between disability, measured by NDI total score, and pain severity, obtained by PPI. The Pearson correlation test was used to investigate the correlation between the disability and neck pain duration. Statistical analyzes were processed in the Statistical Package for Social Sciences, version 15.0.1 (SPSS Inc., Chicago, IL).

\section{Results}

Clinical demographic data are presented in Table 1. According to Br-MPQ schematic drawing, the location of the pain ranged between the neck (90\%), head (19\%) and shoulder (45\%), either unilateral or bilaterally. The most commonly freely chosen words to characterize perceived neckpain were "weight", "tension", "holding", "uncomfortable" and "pressure". From the total of 82 words from PRI categories, the mean number of words chosen to characterize the pain was $10( \pm 2.62)$ out of 20 words.

The most frequently standardized selected words are set out in Table 2. The most significant category of pain, revealed by the PRI weighted score, was the Sensorial category, in which $22(\sim 70 \%)$ participants 
presented most of their pain perception. Table 3 reveals higher means for sensory and evaluative categories, which contains words describing the general painful experience. As to PPI results, $40 \%$ of the participants described the intensity of their pain as moderate, with mean value of 1.23 (0.76), between mild and moderate categories (Table 3). No participants described their pain in strong, violent or unbearable categories. Finally, pain intensity and disability were moderate, positive and significantly correlated $(\mathrm{r}=$ $0.36, p=0.046)$. Disability and neck pain duration were not significantly correlated $(r=0.03, p>0.05)$.

Table 1 - Participants' sociodemographic characteristics

$$
(n=31)
$$

\begin{tabular}{ll}
\hline Variables & Mean (SD) \\
\hline Sex & 26 female, 5 male \\
Age (years) & $29.65(8.79)$ \\
Body mass (Kg) & 62.78 \\
Pain duration (months) & $57(48)$ \\
Height (cm) & $166.9(10.6)$ \\
NDI & $9.77(3.34)$ \\
\hline
\end{tabular}

Note: Source: Authors. $\mathrm{SD}=$ Standard deviation. NDI= Neck Disability Index.

Table 2 - Br-MPQ most frequently chosen words selected by participants $(n=31)$

\begin{tabular}{ll}
\hline Words & $\begin{array}{l}\text { \% of participants who } \\
\text { selected }\end{array}$ \\
\hline "Tugging" & 35,5 \\
"Pressing" & 38,7 \\
"Drawing" & 51,6 \\
"Hot" & 32,2 \\
"Aching" & 41,9 \\
"Heavy" & 51,6 \\
"Tiring" & 32,2 \\
"Annoying" & 38,7 \\
"Blinding" & 35,5 \\
"Troublesome" & 64,5 \\
"Tight" & 32,2 \\
"Spreading" & 48,4 \\
"Taut" & 64,5 \\
\hline
\end{tabular}

Note: Source: Authors.
Table 3 - Participants' Pain Rating Index (PRI) and Present Pain Intensity (PPI) score values $(\mathrm{n}=31)$

\begin{tabular}{ll}
\hline $\begin{array}{l}\text { PRI Category (maximum } \\
\text { score) }\end{array}$ & Mean (SD) \\
\hline Sensorial $(\mathrm{x} / 34)+$ & $0.36(0.13)$ \\
Affective $(\mathrm{y} / 17)$ & $0.27(0.17)$ \\
Evaliative $(\mathrm{z} / 5)$ & $0.34(0.18)$ \\
Miscellaneous (k/12) & $0.19(0.11)$ \\
\hline & \\
\hline PPI & $\mathbf{n}(\%)$ \\
\hline 0 - No pain & $6(19.35 \%)$ \\
1- mild & $12(38.71 \%)$ \\
2- discomforting & $13(41.94 \%)$ \\
3- distressing & 0 \\
4- horrible & 0 \\
5- excrutiating & 0 \\
\hline
\end{tabular}

Note: Source: Authors. $+\mathrm{x}, \mathrm{y}$, z e k represent the sum of scores for Sensory, Affective, Evaliative and Miscellaneous of Pain categories, respectively.

\section{Discussion}

Pain has a multidimensional nature, and its presentation varies according to the structure affected and the type of associated dysfunction patterns (18). According to the International Association for the Study of Pain (IASP-1994), an individual learns the meaning of the word "pain" through experiences related to injuries from the beginning of life, thus the experience of pain is always personal and carries subjectivity. Chronic pain is defined as that with no apparent neuropathic or nociceptive damage or dysfunction, but persists beyond the normal time required for tissue healing, bringing challenge to generate satisfactory outcomes through pharmacological and non-pharmacological treatments (21).

Thus, it is important to evaluate pain comprehensively, especially in chronic musculoskeletal conditions, such as chronic neck pain, so that we can adequately identify the specificities and individualities of these patients and optimize the effectiveness of our interventions. The analogue or numeric scale of pain is the most common tool to determine the intensity of chronic neck pain $(4,22)$. These scales provide rapid information on pain severity; however they are limited to address several other aspects that are involved in the perception of pain in individuals with chronic neck pain. From this perspective, it is 
important to objectively assess features that address both quantitative and qualitative aspects of pain. BrMPQ is useful for detecting the location of the patient's pain and treatments already performed, as well as the characterization aspects most relevant to neck pain (17). In spite of requiring more time in its application, with practice examiners become able to apply Br-MPQ quickly and efficiently, especially in young adult individuals, whom composed the present sample.

Br-MPQ questionnaire revealed that the majority of participants selected the sensorial-discriminative word group to qualify their pain, which refers to the mechanical, thermal and spatial properties of pain $(17,18)$. These findings will assist phyisiotherapists in identifying the most common pain patterns in this population, thus facilitating a more accurate investigation of patients' perception of pain nature and impact in their routine. The sensorial dimension identifies that chronic neck pain is predominantly mechanical in this sample, which reaffirms the importance of rehabilitative interventions such as stabilization exercises and manual therapy to improve local mechanical neck dysfunctions. Our results reinforce the need to represent the sensorial dimension furthermore the affective one as the main Br-MPQ areas to investigate in those with chronic neck pain (23).

International studies use this instrument as a measure for both evaluation and investigation of the effect of treatment in individuals with chronic neck pain or cervicobrachialgia (23-25). Lee et al. (25) compared the sensorial and affective categories of MPQ among groups of individuals with treated neck pain, with untreated cervical pain and no cervical pain. The sensorial dimension was higher in individuals with pain with or without treatment, when compared with those without neck pain $(\mathrm{F} 1.52=$ 31.27, p < 0.01, F1.52 = 14 ( $\mathrm{P}<0.01, \mathrm{p}<0.01$, respectively). The affective dimension was higher in patients with treated neck pain compared to the other groups $(\mathrm{F} 1.52=31.27, \mathrm{p}<0.01)$. Chow et al. (23) when comparing groups of patients using laser therapy and placebo treatment for pain as a primary endpoint, also investigated the difference between groups for the affective and sensory dimensions before and after intervention. They did not identify any differences between groups for these dimensions (between groups differences of $-1.5, p=0.50$, and -0.6 , $\mathrm{p}=0.32$, respectively).
We found no data on the application of this questionnaire in Brazilians with chronic neck pain. We identified studies with Brazilian patients with complaints of low back pain (LBP). In Brazil, Marques et al. (26) used the Br-MPQ questionnaire to investigate the characteristics of chronic LBP in 18 individuals with a mean age of 51 years and found similar means for representing pain in the sensory $(41 \%$ of the sample) and affective (45\%). The relevance of these categories for LBP is confirmed by international literature $(27,28)$. Those with chronic pain present mechanical and often-behavioral changes that facilitate the perpetuation of pain due to associated affective difficulties (29). In our study, the main dimension observed was sensory, when compared with the affective dimension seen by Marques et al. (26). Nevertheless, emotional factors such as work-related stress are risk factors for chronic neck pain, and the interference of pain in these aspects can be inferred by the words chosen in the affective category (30).

Facci et al. (31) also evaluated individuals with chronic low back pain prior to intervention comparing the effects of TENS and interferential currents on these individuals, and observed that the number of words chosen varied between 10 and 13 descriptors in the PRI category, with a significant difference between the number of words chosen before and after intervention. Inferring these findings to the context of this research, the Br-McGill questionnaire may be useful to compare the efficacy of proposed treatments for chronic neck pain reduction by altering the number of words chosen after the selected intervention (31). Often, the patient may report no change in the numerical score of the intensity of their pain, but their reduction may be indicated in other McGill categories, and the effectiveness of an analgesia intervention may thus be more widely evaluated.

As to the use of NDI for the assessment of disability caused by pain, results indicated participants were moderately disabled, that is they altered, but did not interrupt, their daily activities because of the pain experienced, despite the chronicity of the complaint. This statement can be proved by the non-significant correlation between pain duration and disability. On the contrary, disability was significantly associated with pain severity. Ferreira et al. (27) indicated that levels of disability are associated with levels of neuromuscular dysfunction in the presence of spinal pain. Vernon et al. (32) results were similar to this study for patients with neck pain. Indeed, our results 
point to an association between physical disability and pain in individuals with neck pain, reinforcing the importance of adequately approaching both pain and disability in this population aiming to improve the functioning. Noteworthy, the magnitude of this correlation indicates that there are other factors besides the existence of pain, which must also be investigated as contributing to the disability in neck pain.

Some limitations of the study include the fact that there were few male volunteers in the study sample $(\mathrm{n}=5)$. Also, all participants were active adults, which limits the generalization of the results to older patients. In addition, some participants presented painless or mild intensity at the time of application of the questionnaires. We believe that although participants had low levels of pain, this had not great influence on questionnaires results, since all of them had both history of neck pain at least three months prior to data collection. Furthermore, their pain experience interfered in its activities over this time, according to inclusion criteria. This reinforces the existence of chronicity associated with limitations in activity and participation in them. Notably, Br-MPQ brings the evaluation of the painful experience not for one timepoint, but during the current period of the complaint, accepting broader responses in relation to it. Thus, Br-MPQ identifies multidimensional aspects linked to subjective and individual painful perceptions, and present findings encourages its use for exploration in new studies, as well as its applicability in clinical practice to approach those suffering from chronic neck pain.

\section{Conclusion}

The present results identified qualitative and quantitative aspects related to the impact of chronic neck pain, and identified the predominance of pain related sensorial aspects, as well as those related to the general pain experience. In addition, the moderate association between physical disability and pain suggests the importance of appropriately addressing both changes to control symptoms and, in particular, optimize functioning of those who suffer from chronic neck pain. The Br-MPQ and NDI questionnaires revealed to be useful tools for the multidimensional evaluation of patients with chronic neck pain, and future studies should use these instruments to improve the understanding of pain and disability related to this population. Moreover, we suggest investigations that further explore the association of the findings of these instruments with physical therapist findings in body function and structure alterations in the cervical segment.

\section{Acknowledgements}

Fabianna Resende de Jesus-Moraleida received an scholarship from Fundacao de Amparo a Pesquisa de Minas Gerais (FAPEMIG) during her Masters Program in Post Graduate Program in Rehabilitation Sciences (UFMG).

\section{References}

1. Hoy D, March L, Woolf A, Blyth F, Brooks P, Smith E, et al. The global burden of neck pain: estimates from the global burden of disease 2010 study. Ann Rheum Dis. 2014;73(7):1309-15.

2. Carroll LJ, Hogg-Johnson S, Côté P, van der Velde G, Holm LW, Carragee EJ, et al. Course and prognostic factors for neck pain in workers: results of the Bone and Joint Decade 2000-2010 Task Force on Neck Pain and Its Associated Disorders. Spine. 2008;33(4):S93-100.

3. Côté P, Cassidy JD, Carroll LJ, Kristman V. The annual incidence and course of neck pain in the general population: a population-based cohort study. Pain. 2004;112(3):267-73.

4. Hogg-Johnson S, van der Velde G, Carroll LJ, Holm LW, Cassidy JD, Guzman J, et al. The burden and determinants of neck pain in the general population: results of the Bone and Joint Decade 2000-2010 Task Force on Neck Pain and Its Associated Disorders. J Manipulative Physiol Ther. 2009;32(2 Suppl):S46-60.

5. Borghouts JA, Koes BW, Vondeling H, Bouter LM. Costof-illness of neck pain in The Netherlands in 1996. Pain. 1999;80(3):629-36.

6. Côté P, Kristman V, Vidmar M, Van Eerd D, Hogg-Johnson S, Beaton D, et al. The prevalence and incidence of work absenteeism involving neck pain: a cohort of Ontario lost-time claimants. Spine. 2008;33(4):S192-8. 
7. Nyman T, Grooten WJ, Wiktorin C, Liwing J, Norrman L. Sickness absence and concurrent low back and neck-shoulder pain: results from the MUSIC-Norrtalje study. Eur Spine J. 2007;16(5):631-8.

8. Falla D.Unravelling the complexity of muscle impairment in chronic neck pain. Man Ther. 2004;9(3):125-33.

9. Hush JM, Michaleff Z, Maher CG, Refshauge K. Individual, physical and psychological risk factors for neck pain in Australian office workers: a 1-year longitudinal study. Eur Spine J. 2009;18(10):1532-40.

10. Cagnie B, Danneels L, Van Tiggelen D, De Loose V, Cambier D. Individual and work related risk factors for neck pain among office workers: a cross sectional study. Eur Spine J. 2007;16(5):679-86.

11. Marcus M, Gerr F, Monteilh C, Ortiz DJ, Gentry E, Cohen $S$, et al. A prospective study of computer users: II. Postural risk factors for musculoskeletal symptoms and disorders. Am J Ind Med. 2002;41(4):236-49.

12. Hannan LM, Monteilh CP, Gerr F, Kleinbaum DG, Marcus M. Job strain and risk of musculoskeletal symptoms among a prospective cohort of occupational computer users. Scand J Work Environ Health. 2005;31(5):375-86.

13. Meziat FN, Silva GA. Invalidez por dor nas costas entre segurados da Previdência Social do Brasil. Rev Saúde Pública. 2011;45:494-502.

14. Santos CC, Resende MA, Aguiar V, Magno F, Pereira LSM. Aplicação da versão brasileira do questionário de dor Mcgill em idosos com dor crônica. Acta Fisiatr. 2006;13(2):75-82.

15. Castro CS.A formação lingüística da dor - versão brasileira do questionário McGill de dor [dissertation]. São Paulo: Universidade Federal de São Carlos; 1999.

16. Melzack,R.The McGill Pain Questionnaire: major properties and scoring methods. Pain. 1975;1(3):277-99.

17. Cook C, Richardson JK, Braga L, Menezes A, Soler X, Kume P, et al. Cross-cultural adaptation and validation of the Brazilian Portuguese version of the Neck Disability Index and Neck Pain and Disability Scale. Spine. 2006;31(14):1621-7.
18. Gorenstein C, Pompeia S, Andrade L. Scores of Brazilian University students on the Beck Depression and the State Trait Anxiety Inventories. Psychol Rep. 1995;77(2):635-41.

19. McCarthy MJ, Grevitt MP, Silcocks P, Hobbs G. The reliability of the Vernon and Mior neck disability index, and its validity compared with the short form-36 health survey questionnaire. Eur Spine J. 2007;16(12):2111-7.

20. Ferreira ML, Borges BM, Rezende IL, Carvalho LP, Soares LP, Dabes RA, et al. Are neck pain scales and questionnaires compatible with the international classification of functioning, disability and health? A systematic review. Disabil Rehabil. 2010;32(19):1539-46.

21. Apkarian AV, Sosa Y, Sonty S, Levy RM, Harden RN, Parrish TB, et al. Chronic Back Pain Is Associated with Decreased Prefrontal and Thalamic Gray Matter Density. J Neurosci. 2000;24(46):10410-5.

22. O'Leary S, Falla D, Hodges PW, Jull G, Vicenzino B. Specific therapeutic exercise of the neck induces immediate local hypoalgesia. J Pain. 2007;8(11):832-9.

23. Chow RT, Heller GZ, Barnsley L. The effect of 300 $\mathrm{mW}, 830 \mathrm{~nm}$ laser on chronic neck pain: a doubleblind, randomized, placebo-controlled study. Pain. 2006;124(1-2):201-10.

24. Allison GT, Nagy BM, Hall T. A randomized clinical trial of manual therapy for cervico-brachial pain syndrome - a pilot study. Man Ther. 2002;7(2):95-102.

25. Lee H, Nicholson LL, Adams RD. Neck muscle endurance, self-report, and range of motion data from subjects with treated and untreated neck pain. J Manipulative Physiol Ther. 2005;28(1):25-32.

26. Marques AP, Rhoden L, Siqueira JO, João SMA. Pain evaluation of patients with fibromyalgia, osteoarthritis, and low back pain. Rev Hosp Clin Fac Med Sao Paulo. 2001;56(1):5-10.

27. Ferreira PH, Ferreira ML, Maher CG, Refshauge K, Herbert RD, Hodges PW. Changes in recruitment of transversus abdominis correlate with disability in people with chronic low back pain. Br J Sports Med. 2010;44(16):1166-72. 
28. Hiebert R, Campello MA, Weiser S, Ziemke GW, Fox BA, Nordin M. Predictors of short-term work-related disability among active duty US Navy personnel: a cohort study in patients with acute and subacute low back pain. Spine J. 2012;12(9):806-16.

29. Bair MJ, Wu J, Damush TM, Sutherland JM, Kroenke K. Association of depression and anxiety alone and in combination with chronic musculoskeletal pain in primary care patients. Psychosom Med. 2008;70(8):890-7.

30. Kääriä S, Laaksonen M, Rahkonen O, Lahelma E, LeinoArjas P. Risk factors of chronic neck pain: A prospective study among middle-aged employees. Eur J Pain. 2012;16(6):911-20.
31. Facci LM, Nowotny JP, Tormem F, Trevisani VFM. Effects of transcutaneous electrical nerve stimulation (TENS) and interferential currents (IFC) in patients with nonspecific chronic low back pain: randomized clinical trial. Sao Paulo Med. J. 2011;129(4):206-16.

32. Vernon H, Mior S.The Neck Disability Index: a study of reliability and validity. J Manipulative Physiol Ther. 1991;14(7):409-15.

Received in 02/03/2016

Recebido em 03/02/2016

Approved in 02/24/2017

Aprovado em 24/02/2017 